\title{
Mixture Design Approach on the Physical Properties of Lignin-Resorcinol-Formaldehyde Xerogels
}

\author{
Chris D. Castro and Germán C. Quintana \\ Grupo Pulpa y Papel, Facultad de Ingeniería Química, Universidad Pontificia Bolivariana, Sede Central Medellín, \\ Circular 1 No. 70-01, Medellín, Colombia \\ Correspondence should be addressed to Germán C. Quintana; german.quintana@upb.edu.co
}

Received 27 May 2015; Revised 17 July 2015; Accepted 2 September 2015

Academic Editor: Antje Potthast

Copyright (C) 2015 C. D. Castro and G. C. Quintana. This is an open access article distributed under the Creative Commons Attribution License, which permits unrestricted use, distribution, and reproduction in any medium, provided the original work is properly cited.

\begin{abstract}
Organic xerogels were functionalized by incorporating sugarcane bagasse lignin from soda pulping black liquor, not used so far in this materials, with the aim of introducing new functional groups on traditional gels that could improve its adsorptive capacity. Two mixing designs were applied to identify the reactive combinations that allow a well gel formation and to adjust models that predict physical properties. The designs study five components: resorcinol $(R, 0.04-0.3)$, lignin $(L, 0.004-0.14)$, formaldehyde $(F$, $0.08-0.17)$, water $(W, 0.45-0.8)$, and $\mathrm{NaOH}(C, 0.0003-0.0035)$. The first experimental design was an extreme vertices design and its results showed shrinkage between 4.3 and 59.7 and a bulk density from 0.54 to 1.3 ; a mass ratio $L R / F$ near 1.5 was required for gel formation. In the second design a D-Optimal was used to achieve better adjusted coefficients and incorporate the largest possible amount of lignin in the gels. Bulk density varies from 0.42 to 0.9 , shrinkage varies from 3.42 to 25.35 , and specific surface area reaches values of $451.86 \mathrm{~m}^{2} / \mathrm{g}$ with $13 \%$ lignin and $270 \mathrm{~m}^{2} / \mathrm{g}$ with $27 \%$ lignin. High catalyst content improves lignin dissolution and increase shrinkage and bulk density of xerogels and bulk density. Lignin contributes to reducing shrinkage and specific surface area due to his compact and rigid structure.
\end{abstract}

\section{Introduction}

The first organic gel was obtained by Pekala in a solgel polymerization of resorcinol and formaldehyde under alkaline conditions and supercritical drying [1]; this was called aerogel. If the method of drying the gel is at subcritical conditions, the the gel is called xerogel; under freezing conditions, is called cryogel. The organic gels are suitable for several applications like catalysis, insulation, supercapacitors, and hydrogen storage, due to their properties like high surface area, controlled porous structure, low bulk density, and high electric conductivity [2-4]. Organic gel production costs are high; therefore new process and raw materials have been studied to obtain a product commercially attractive [5]. Besides resorcinol, other phenolic compounds have been used: phenol [6, 7], tannins [8, 9], 2,4-dihydroxybenzoic acid [10], pyrocatechol [11], technical lignin [12-16], and so forth. Furfural also has been used as crosslink $[17,18]$.
After cellulose, lignin is the second most abundant biopolymer, is a low cost material, and has a phenolic nature [19]. Lignin is an excellent precursor of activated carbon and bioadsorbent, due to their high molecular weight polymer complex structure and the presence of high electron density functional groups such as carboxylics, carbonyls, hydroxyls and ketones [20-23]. Lignin has already been used in the manufacture of lignin-phenol-formaldehyde resins and adhesives [24, 25], so it can be used as a cheap raw material to prepare organic and carbon gels $[12,13,16]$.

A catalyst is used to adjust the $\mathrm{pH}$ of the solution in the organic gel reaction. Several reagents have been used as catalyst, sodium or potassium carbonates [26, 27], acetic acid [28], nitric acid [29], oxalic acid or paratoluenesulfonic acid [27], sodium hydroxide $[13,15,30]$, and so forth. $R / C$ ratio is used as controlling parameter because $\mathrm{pH}$ changes continuously throughout the reaction [31]. Sodium hydroxide 
was used like catalyst in traditional gels and $\mathrm{NaOH}$ solution dissolves lignin [32].

Mixture design has not been applied in organic gels. Zanto et al. [33] used a full factorial design for studying interactions between $\mathrm{pH}$, weight percent of solids, and pyrolysis temperature and their effects on carbon gels surface area, pore volume, and electrochemical double-layer capacitance. Mixture design is a statistics tool for modeling blends, where the variables are the components proportions. The proportions must always sum to 1 , and thus the last component amount is dictated by the sum of all the others. The measured response is assumed to depend only on components amount. Mixture models allow interpolation to determine the mixture that will produce a desired maximum or minimum response [34].

In this work models that predict the physical properties of lignin based organic xerogels are presented, identifying the reactive combinations that permit a maximum lignin incorporation with a good xerogel properties. This kind of lignin has not been used previously in organic xerogel formation, so the chemistry and limits for its employ are unknown. Models for properties of xerogels have not been proposed, although some systematic studies have been carried out in organic xerogels without lignin [35], tannin carbon xerogels [36], and carbon xerogels [37].

\section{Experimental}

2.1. Materials. Soda lignin was precipitated from sugar cane bagasse soda pulping black liquor by acidification with sulfuric acid at $98 \%$ until the $\mathrm{pH}$ of the resultant solution was close to 2 . The precipitate was washed with water until the $\mathrm{pH}$ of the rinse was close to 6 . Lignin was dried in an oven at $60^{\circ} \mathrm{C}$ for $24 \mathrm{~h}$, and a dark-brown powder was recovered.

Organic gels were synthesized from Resorcinol 99\% (Panreac, research grade) and Formaldehyde 37\% w/v stabilized with methanol (Panreac, research grade), solid $\mathrm{NaOH}$ (Merck, research grade), and deionized water.

2.2. Xerogels Preparation. The gels were prepared according to the method established by Pekala [1]; five components (lignin, resorcinol, formaldehyde, water, and $\mathrm{NaOH}$ ) were mixed in a magnetic stirrer at room temperature and then transferred into a glass vial $(10 \mathrm{~mL})$. The vial was sealed and then was put into a water bath $\left(85^{\circ} \mathrm{C}\right)$ to polymerize for five days. The gels were retired from the vial and were cut into cylindrical pieces and immersed in pure ethanol during three days; the solvent was replaced every day. Drying was carried out at $40^{\circ} \mathrm{C}$ for $48 \mathrm{~h}$.

The study of the effect of lignin addition on xerogels was conducted in two stages; first step was an extreme vertices mixing design (EV), which will study the effects of the five components in twenty runs. Fraction levels are listed in Table 1 and were based on previous papers that evaluated lignin addition on aerogels and cryogels $[12,13,15]$. The matrix design is shown in Table 2 , along with $\mathrm{pH}$, bulk density, and shrinkage results.

A second mixing design was performed, based on those previous results, to obtain more information in the region
TABLE 1: Components levels in mass, first, and second design.

\begin{tabular}{lcccc}
\hline \multirow{2}{*}{ Component } & \multicolumn{2}{c}{ EV } & \multicolumn{2}{c}{ DO } \\
& Low level & High level & Low level & High level \\
\hline Resorcinol & 0.04 & 0.3 & $0.23^{\mathrm{a}}$ & $0.23^{\mathrm{a}}$ \\
Lignin & 0.004 & 0.03 & 0.0315 & 0.14 \\
Formaldehyde & 0.08 & 0.2 & $0.17^{\mathrm{a}}$ & $0.17^{\mathrm{a}}$ \\
Water & 0.45 & 0.8 & 0.456 & 0.56 \\
$\mathrm{NaOH}$ & 0.0003 & 0.0005 & 0.0004 & 0.0035 \\
\hline
\end{tabular}

${ }^{\mathrm{a}}$ Fixed values from EV.

TABLE 2: Matrix and results for extreme vertices mixing design (mass fraction).

\begin{tabular}{lcccccccc}
\hline Number & $R$ & $L$ & $F$ & $C$ & $W$ & $\mathrm{pH}$ & $\begin{array}{c}\rho_{b} \\
\left(\mathrm{~g} / \mathrm{cm}^{3}\right)\end{array}$ & $\begin{array}{c}\mathrm{Rs} \\
(\%)\end{array}$ \\
\hline 1 & 0.04 & 0.004 & 0.08 & 0.0003 & 0.8757 & 6.6 & 0.795 & 59.77 \\
2 & 0.3 & 0.004 & 0.08 & 0.0003 & 0.6157 & 5.87 & $\mathrm{~nm}^{\mathrm{a}}$ & 42.35 \\
3 & 0.04 & 0.03 & 0.08 & 0.0003 & 0.8497 & 5.15 & $\mathrm{ng}^{\mathrm{b}}$ & $\mathrm{ng}^{\mathrm{b}}$ \\
4 & 0.3 & 0.03 & 0.08 & 0.0003 & 0.5897 & 4.32 & 1.129 & 42.56 \\
5 & 0.04 & 0.004 & 0.2 & 0.0003 & 0.7557 & 6.53 & 0.881 & 59.18 \\
6 & 0.3 & 0.004 & 0.2 & 0.0003 & 0.4957 & 5.8 & 0.547 & 4.86 \\
7 & 0.04 & 0.03 & 0.2 & 0.0003 & 0.7297 & 4.86 & $\mathrm{ng}^{\mathrm{b}}$ & $\mathrm{ng}$ \\
8 & 0.3 & 0.03 & 0.2 & 0.0005 & 0.4695 & 4.84 & 0.543 & 4.29 \\
9 & 0.3 & 0.03 & 0.2 & 0.0003 & 0.4697 & 4.36 & 0.584 & 4.98 \\
10 & 0.04 & 0.004 & 0.08 & 0.02 & 0.856 & 8.47 & $\mathrm{~nm}^{\mathrm{b}}$ & 52.87 \\
11 & 0.3 & 0.004 & 0.08 & 0.02 & 0.596 & 7.85 & 0.656 & 35.77 \\
12 & 0.04 & 0.03 & 0.08 & 0.02 & 0.83 & 8.65 & $\mathrm{~nm}^{\mathrm{a}}$ & 49.17 \\
13 & 0.3 & 0.03 & 0.1805 & 0.02 & 0.4695 & 7.64 & 1.091 & 20.69 \\
14 & 0.3 & 0.03 & 0.08 & 0.02 & 0.57 & 7.73 & 0.770 & 35.05 \\
15 & 0.04 & 0.004 & 0.2 & 0.02 & 0.736 & 8.53 & $\mathrm{~nm}^{\mathrm{a}}$ & 54.24 \\
16 & 0.3 & 0.0105 & 0.2 & 0.02 & 0.4695 & 7.17 & 1.098 & 22.44 \\
17 & 0.3 & 0.004 & 0.2 & 0.02 & 0.476 & 7.15 & 1.151 & 22.23 \\
18 & 0.2805 & 0.03 & 0.2 & 0.02 & 0.4695 & 7.15 & 1.188 & 22.70 \\
19 & 0.04 & 0.03 & 0.2 & 0.02 & 0.71 & 8.2 & $\mathrm{~nm}^{\mathrm{a}}$ & 54.18 \\
20 & 0.04 & 0.004 & 0.08 & 0.0003 & 0.8757 & 6.25 & 0.877 & 59.04 \\
\hline
\end{tabular}

${ }^{\mathrm{a}} \mathrm{nm}$ : not measurable; ${ }^{\mathrm{b}} \mathrm{ng}$ : not gel formation.

with best gel formation. For maximum accuracy in the estimating regression coefficients, a D-Optimal (DO) mixing design was created to study the effect of lignin $(L)$, water $(W)$, and $\mathrm{NaOH}(C)$ on gels properties, for this design the mass fraction of resorcinol $(R)$ and formaldehyde $(F)$ were fixed, Table 1. Both designs were analyzed with Statgraphics Centurion XVI Version 16.1.18.

\subsection{Characterization Methods}

2.3.1. Lignin Molecular Weight. Lignin molecular weight distribution was determined by size exclusion chromatography (SEC) in a Sephadex G-75 column $(57 \mathrm{~cm} \times 1.8 \mathrm{~cm})$ eluted at $1 \mathrm{~mL} / \mathrm{min}$ with $0.5 \mathrm{M}$ sodium hydroxide using an AKTA 10 GE chromatograph set with a UV detector fixed at $280 \mathrm{~nm}$. Inject $1 \mathrm{~mL}$ of sample at a concentration of $1 \mathrm{mg} / \mathrm{mL}$. To allow 
the calculation of molecular weight $(\mathrm{Mw})$, a calibration of the chromatographic column was performed with proteins of known molecular weight: albumin $(66 \mathrm{kDa})$, carbonic anhydrase $(29 \mathrm{kDa})$, cytochrome c $(12.4 \mathrm{kDa})$, aprotinin $(6.5 \mathrm{kDa})$, and acetone (28 Da) [38].

2.3.2. Lignin and Xerogels Functional Groups. Lignin and some xerogels were analyzed by Total Attenuated Reflectance (ATR). All spectra were constructed at the region from 4000 to $400 \mathrm{~cm}^{-1}$ with a resolution of $4 \mathrm{~cm}^{-1}$ and 64 scans. For ATR was used a FTIR spectrometer (Nicolet 6700) equipped with an ATR crystal in type IIA diamond mounted on tungsten carbide. Diamond ATR has a sampling area of approximately $0.5 \mathrm{~mm}^{2}$, which applies a constant pressure to each sample.

2.3.3. Solubility Test. It was performed to some xerogels with lignin and one without lignin. $25 \mathrm{~mL}$ of a $\mathrm{pH} 12$ solution was added to $0.1 \mathrm{~g}$ of sample (dry basis). The mixture was shaken for $24 \mathrm{~h}$ at $22^{\circ} \mathrm{C}$. Then it was filtered and the lignin concentration in the liquid was measured with a UV-1800 spectrometer (Shimadzu) at $280 \mathrm{~nm}$ where maximum is observed. Lignin concentration was calculated based on a calibration curve established with a series of lignin solution with differing concentrations.

2.3.4. Scanning Electron Microscopy (SEM). Some samples were observed in a microscope SEM-EDX Hitachi S-3400 N to compare their morphology. It was performed at low voltage, especial mode of operation for nonconducting materials.

2.3.5. Xerogels Density, Porosity and Pore Texture. Bulk density, $\rho_{b}\left(\mathrm{~g} / \mathrm{cm}^{3}\right)$, was estimated by direct measures of monolith weight and volume. Skeletal density, $\rho\left(\mathrm{g} / \mathrm{cm}^{3}\right)$, was measured with a helium pycnometry (Accupyc II 1340 Micromeritics, USA). Radial shrinkage, Rs (\%), was determined measuring the monolith diameter before and after drying and the overall porosity, $\varepsilon(\%)$, was calculated from skeletal and bulk densities as $\varepsilon=1-\rho / \rho_{b}$.

Specific surface area, $S_{\mathrm{BET}}$, was determined by the BET method [39], using a gas sorption system (Quantachrome Instruments, USA) after outgassing samples overnight under high vacuum. The mesopore volume, $V_{\text {meso BJH }}\left(\mathrm{cm}^{3} / \mathrm{g}\right)$, was calculated from Barrett-Joyner-Halenda (BJH) equation applied to the isotherm desorption branch [40]; and total pore volume, $V_{0.95}\left(\mathrm{~cm}^{3} / \mathrm{g}\right)$, was the volume of liquid nitrogen adsorbed at a relative pressure $P / P_{0}=0.95$ [41].

\section{Results and Discussions}

3.1. Lignin Molecular Weight. Figure 1 shows lignin molecular weight distribution. Two peaks are observed: one near $4000 \mathrm{~g} / \mathrm{mol}$ and another smaller in $27000 \mathrm{~g} / \mathrm{mol}$; it is similar to molecular weight distribution of wheat straw lignin [42]. Lignin has a weight average molecular weight $(\mathrm{Mw})$ of $6492 \mathrm{~g} / \mathrm{mol}$ and a number average molecular weight $(\mathrm{Mn})$ of $3191.44 \mathrm{~g} / \mathrm{mol}$; Mw obtained is higher than

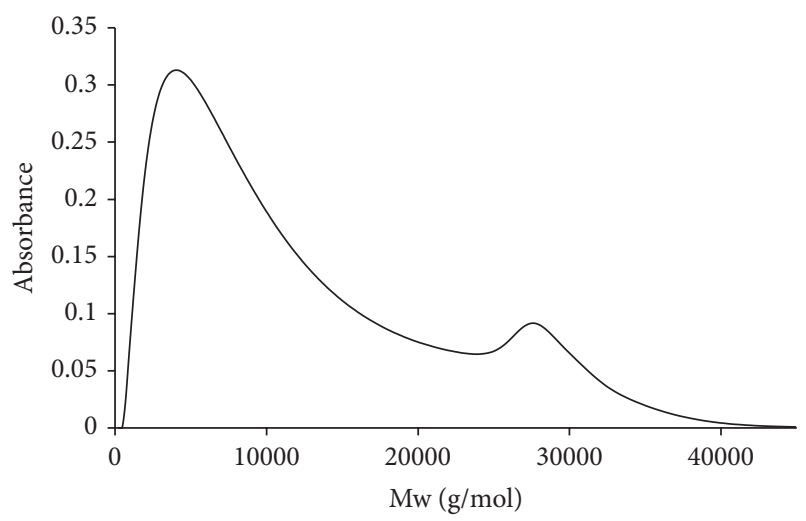

FIGURE 1: Lignin molecular weight distribution.

lignin-carbohydrate complexes $\mathrm{Mw}$ that have values between $600 \mathrm{~g} / \mathrm{mol}$ and $1500 \mathrm{~g} / \mathrm{mol}$. Common nonwood lignins have Mw between $1100 \mathrm{~g} / \mathrm{mol}$ and $2100 \mathrm{~g} / \mathrm{mol}$ and analytical lignins have $\mathrm{Mw}$ from $7700 \mathrm{~g} / \mathrm{mol}$ to $8500 \mathrm{~g} / \mathrm{mol}$ [19].

The intermediary value found in this work is due to the fact that lignin was precipitated from black liquor of soda pulping, where it was subjected to degradation reactions [19]; also it has a high amount of precipitated xylans fractions, which have a low molecular weight [43]. Dispersity index $(\mathrm{Mw} / \mathrm{Mn})$ is 2.03 and is similar with the values reported for lignins from agricultural waste [44].

3.2. Extreme Vertices Mixing Design for Xerogels Formulation. Design results are shown in Table 2; in most cases there was gel formation, except for assays 3 and 7 , corresponding to minimum $R / L$ and minimum catalyst mass fraction. For assays $2,10,12,15$, and 19, although gel formation occurred, they cracked into small pieces because of the capillary forces during convective drying [45]; unfortunately for these xerogels, bulk density measure was not possible but in some of them were feasible to measure their shrinkage. Due to the few measurable bulk densities, it was not possible to adjust a model from this mixture design experiment.

Table 3 presents the ANOVA for radial shrinkage. Quadratic model was adjusted with high value of $R^{2}=98.95$ and $P$ value $<0.05$. Statistical data indicates that the regression models are adequate in predicting the xerogel shrinkage.

The model for shrinkage was (pseudocomponents mass fraction) as follows:

$$
\begin{aligned}
\mathrm{Rs}= & -75.3534 * R-6132.77 * L-279.986 * F \\
& +48787.5 * C+60.8953 * W+6911.85 * R * L \\
& +601.552 * R * F-50837.1 * R * C+287.138 \\
& * R * W+6960.1 * L * F-46658.2 * L * C \\
& +6720.24 * L * W-50093.1 * F * C+461.248 \\
& * F * W-51458.9 * C * W .
\end{aligned}
$$

Figures 2(a) and 2(b) show the contour plots when $R / F=1.5$ and 1.4 , respectively, for shrinkage. Contours 
TABLE 3: Statistical properties of variance analysis for the significance of regression models.

\begin{tabular}{lcccccccc}
\hline Property & Regression model & df & Sum of Squares & Mean Square & $F$-test & $P$ value & $R^{2}$ & Ajd. $R^{2}$ - \\
\hline Rs & Quadratic & 14 & 6492.18 & 463.73 & 20.27 & 0.0151 & 98.95 & 94.07 \\
\hline
\end{tabular}

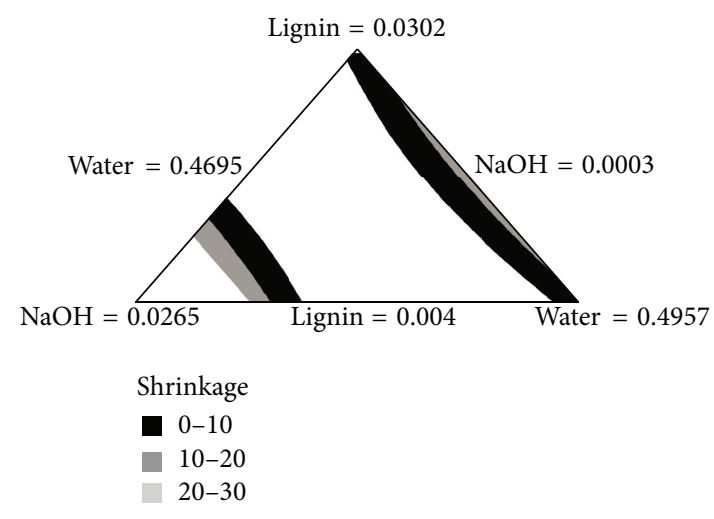

(a) Resorcinol $=0.3$, formaldehyde $=0.2$
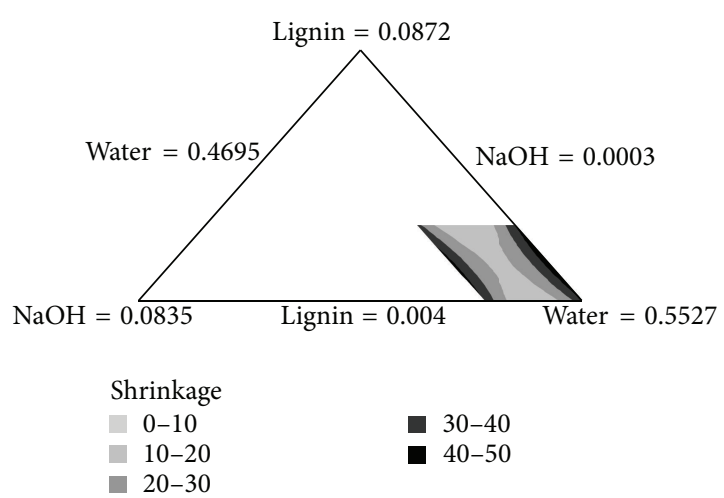

(b) Resorcinol $=0.261$, formaldehyde $=0.182$

FIgURE 2: Contour plots for shrinkage: (a) $R / F$ mass ratio 1.5 ; (b) $R / F$ mass ratio 1.4.

zones are clearly differentiable and the model obtained from the statistical analysis shows a strong interaction between the different components. Higher lignin addition decreases xerogels shrinkage. There is a strong influence of the catalyst fraction on xerogels properties. The initial $\mathrm{pH}$ was found between 4.32 and 8.65 (Table 2) and xerogels with lower shrinkage and bulk density result when a mass ratio $R L / C$ was between 660 and 1100 (molar ratio 240-1100).

Better xerogels formulations occur when the mass ratio $R / F$ is between 1.4 and 1.66 , which corresponds to the stoichiometric molar ratio $(R / F$ around 0.5$)$ and with $50 \%$ solid or more, regardless of the amount of added lignin. Lignin has less reactive sites per molecule than resorcinol $[43,46]$; that is a reason for keeping the stoichiometric molar ratio $R / F$ around 0.5 .

Water effect according to the model is directly proportional to the shrinkage. Three new experiments were made to verify the water effect in the xerogels (Table 4), in these experiments, water mass fractions of $0.6,0.65$ and 0.7 were tested using the next reagents mass ratio: $R / L=2.7, R L / C=$ 122 and $R L / F=1.5$. It was observed that increasing water content in $16 \%$, shrinkage is increased around $360 \%$ and lower xerogels bulk densities are obtained.

Second mixing design was proposed to study the lignin, water, and catalyst effect on xerogels physical properties in detail. In the new design, resorcinol and formaldehyde mass fractions were fixed in 0.23 and 0.17 , respectively, to establish a $R L / F$ ratio between 1.54 and 2.18 in order to ensure xerogels formation and dimensional stability.

3.3. D-Optimal Design. In this D-Optimal design the effect of lignin, water, and $\mathrm{NaOH}$ on xerogels physical properties in 16 runs with four central points was studied. Table 5 listed the matrix experiment with physical results.

Table 6 shows the ANOVA for D-Optimal design. The $P$ value for each model is less than 0.05 displaying a statistically
TABLE 4: Water effect content in xerogels shrinkage and bulk density (mass fraction).

\begin{tabular}{lcccccccc}
\hline Number & $R$ & $L$ & $F$ & $C$ & $W$ & $\mathrm{pH}$ & $\begin{array}{c}\rho_{b} \\
\left(\mathrm{~g} / \mathrm{cm}^{3}\right)\end{array}$ & $\begin{array}{c}\mathrm{Rs} \\
(\%)\end{array}$ \\
\hline 1 & 0.17801 & 0.065 & 0.155 & 0.00199 & 0.6 & 5.68 & 0.393 & 4.98 \\
2 & 0.15625 & 0.057 & 0.135 & 0.00175 & 0.65 & 5.47 & 0.39 & 10 \\
3 & 0.13352 & 0.047 & 0.118 & 0.00148 & 0.7 & 5.77 & 0.531 & 23.06 \\
\hline
\end{tabular}

significant relationship between properties and components with a confidence level of $95.0 \%$.

The best model for all variables was the cubic, except for radial shrinkage where it was especial cubic. They have the highest statistics $R^{2}$ and $P$ values $<0.05$. In these models second-order interactions are included and reflected the complex interactions between the components in xerogels synthesis, even more when they are made with biomolecules [47]. The adjusted models for response variables were (pseudocomponents mass fraction) as follows:

$$
\begin{aligned}
S_{\mathrm{BET}}= & 71.497 * L+58.2649 * W+7.32186 E 7 * C \\
& -2004.33 * L * W-1.11579 E 8 * L * C \\
& -1.11939 E 8 * W * C+7.72769 E 7 * L * W \\
& * C+93.2093 * L * W *(L-W) \\
& +3.83999 E 7 * L * C *(L-C) \\
& +3.87966 E 7 * W * C *(W-C), \\
\rho_{b}= & 0.528478 * L+0.418737 * W-22672.8 * C \\
& +0.449442 * L * W+34654.3 * L * C \\
& +34673.2 * W * C-24051.3 * L * W * C
\end{aligned}
$$


TABle 5: Matrix and results for D-Optimal design (mass fraction).

\begin{tabular}{|c|c|c|c|c|c|c|c|c|c|c|c|}
\hline Number & $R$ & $L$ & $F$ & $C$ & $W$ & $\mathrm{pH}$ & $\rho_{b}\left(\mathrm{~g} / \mathrm{cm}^{3}\right)$ & Rs (\%) & $\varepsilon$ & $S_{\text {BET }}\left(\mathrm{m}^{2} / \mathrm{g}\right)$ & $V_{\text {meso BJH }}\left(\mathrm{cm}^{3} / \mathrm{g}\right)$ \\
\hline 1 & 0.23 & 0.035 & 0.17 & 0.00040 & 0.565 & 3.98 & 0.42 & 3.76 & 0.65 & 6.33 & 0.013 \\
\hline 2 & 0.23 & 0.087 & 0.17 & 0.00195 & 0.512 & 4.97 & 0.49 & 3.42 & 0.60 & 41.35 & 0.104 \\
\hline 3 & 0.23 & 0.140 & 0.17 & 0.00040 & 0.460 & 3.19 & 0.55 & 3.70 & 0.55 & 16.28 & 0.048 \\
\hline 4 & 0.23 & 0.140 & 0.17 & 0.00040 & 0.460 & 3.14 & 0.56 & 4.33 & 0.55 & 15.47 & 0.045 \\
\hline 5 & 0.23 & 0.061 & 0.17 & 0.00118 & 0.538 & 4.7 & 0.45 & 3.72 & 0.63 & 34.08 & 0.082 \\
\hline 6 & 0.23 & 0.032 & 0.17 & 0.00350 & 0.565 & 7.19 & 0.90 & 25.35 & 0.30 & 405.59 & 0.166 \\
\hline 7 & 0.23 & 0.087 & 0.17 & 0.00195 & 0.512 & 4.9 & 0.48 & 4.21 & 0.59 & 38.15 & 0.095 \\
\hline 8 & 0.23 & 0.140 & 0.17 & 0.00350 & 0.457 & 5.21 & 0.58 & 4.22 & 0.52 & 30.11 & 0.093 \\
\hline 9 & 0.23 & 0.140 & 0.17 & 0.00350 & 0.457 & 5.11 & 0.58 & 5.14 & 0.53 & 28.20 & 0.083 \\
\hline 10 & 0.23 & 0.087 & 0.17 & 0.00195 & 0.512 & 4.93 & 0.49 & 3.76 & 0.58 & 40.07 & 0.143 \\
\hline 11 & 0.23 & 0.113 & 0.17 & 0.00118 & 0.486 & 4.02 & 0.52 & 4.04 & 0.56 & 14.56 & 0.051 \\
\hline 12 & 0.23 & 0.104 & 0.17 & 0.00247 & 0.494 & 5.08 & 0.53 & 4.07 & 0.55 & 40.41 & 0.097 \\
\hline 13 & 0.23 & 0.069 & 0.17 & 0.00247 & 0.529 & 5.91 & 0.47 & 4.49 & 0.60 & 226.45 & 0.367 \\
\hline 14 & 0.23 & 0.086 & 0.17 & 0.00350 & 0.511 & 6.51 & 0.50 & 4.65 & 0.58 & 273.05 & 0.355 \\
\hline 15 & 0.23 & 0.035 & 0.17 & 0.00040 & 0.565 & 4.04 & 0.42 & 3.88 & 0.63 & 4.89 & 0.012 \\
\hline 16 & 0.23 & 0.033 & 0.17 & 0.00195 & 0.565 & 6.88 & 0.58 & 13.75 & 0.51 & 451.86 & 0.843 \\
\hline
\end{tabular}

TABLE 6: Major statistical properties of variance analysis for the significance of regression models.

\begin{tabular}{lcccccccc}
\hline Property & Regression model & df & Sum of Squares & Mean Square & $F$-test & $P$ value & $R^{2}$ & Adj. $R^{2}$ \\
\hline$S_{\text {BET }}$ & Cubic & 9 & 326224 & 36247.2 & 46.37 & 0.0001 & 98.58 & 96.46 \\
$\rho_{b}$ & Cubic & 9 & 0.18402 & 0.000216586 & 94.40 & 0.0000 & 99.30 & 98.25 \\
Rs & Especial Cubic & 6 & 475.452 & 79.242 & 57.82 & 0.0000 & 97.47 & 95.78 \\
Porosity & Cubic & 9 & 0.096156 & 0.010684 & 64.65 & 0.0000 & 98.98 & 97.45 \\
\hline
\end{tabular}

$$
\begin{aligned}
& +0.573578 * L * W *(L-W)-11997.8 \\
& * L * C *(L-C)-12001.2 * W * C \\
& *(W-C) \\
\varepsilon= & 0.563069 * L+0.6339 * W+10007.3 * C \\
& -0.124445 * L * W-15243.6 * L * C \\
& -15328.8 * W * C+10589.9 * L * W * C \\
& -0.446082 * L * W *(L-W)+5240.46 \\
& * L * C *(L-C)+5319.45 * W * C \\
& *(W-C), \\
\text { Rs } & 4.45934 * L+3.5636 * W+1001.2 * C \\
& -3.76034 * L * W-1007.31 * L * C \\
& -239.831 * W * C-1434.31 * L * W * C .
\end{aligned}
$$

3.3.1. Specific Surface Area Analysis. $S_{\mathrm{BET}}$ were obtained between 16 and $452 \mathrm{~m}^{2} / \mathrm{g}$. Maximum value reached for $S_{\mathrm{BET}}$ occurred when $\mathrm{NaOH}$ pseudocomponent is $0.013889, R L / C$ $134.9, R / L 6.96$, and initial $\mathrm{pH}$ 6.88. This $S_{\mathrm{BET}}$ is similar to specific surface area obtained in organic xerogels without lignin addition [30, 48-50], or superior [51]. Job et al. (2004) [30] proposed that when $\mathrm{pH}$ increases from 5.45 to 7.35 xerogels turn from micro/macroporous material to microporous material and pass through a maximum, $510 \mathrm{~m}^{2} / \mathrm{g}$, when $\mathrm{pH}$ is equal to 6.50. In this work, better $S_{\mathrm{BET}}$ development takes place when $\mathrm{pH}$ goes from 5.91 to 6.88 (Figure 3). A direct correlation is observed between $C$ mass fraction and $\mathrm{pH}$; however the lignin addition produces a reduction on initial $\mathrm{pH}$ (Figure 4) due to hydroxyl and carboxyl groups present in its structure [52].

Figure 5 shows the surface plot for $S_{\mathrm{BET}}$ with $L$ and $C$ in pseudocomponents. Maximum values for $S_{\mathrm{BET}}$ occurred when $\mathrm{NaOH}$ pseudocomponent is around 0.027 to any lignin fraction and correspond to $R L / C$ mass ratios values between 74 and 105; these values are related to initial $\mathrm{pH}$ value between 5.91 and 7.19 .

Higher lignin content decreases $S_{\mathrm{BET}}$; its effect is greater when the catalyst is in low levels. Chen et al. [12,13] obtained similar results in lignin-resorcinol-formaldehyde aerogels; an $R / L$ ratio value of 1 reduces $S_{\mathrm{BET}}$ from $553 \mathrm{~m}^{2} / \mathrm{g}$ (without lignin) up to $191 \mathrm{~m}^{2} / \mathrm{g}$.

$S_{\mathrm{BET}}$ results obtained in this study are similar to values reported by Grishechko et al. (2013) [15] in the cryogels and aerogels formulations with phenol and lignin; a maximum $S_{\mathrm{BET}}$ value was $500 \mathrm{~m}^{2} / \mathrm{g}$ with a phenol/lignin ratio of 1 at higher initial $\mathrm{pH}$. Tannins and lignin were used for aerogel production [14]; aerogels with higher $S_{\mathrm{BET}}, \sim 475 \mathrm{~m}^{2} / \mathrm{g}$, had a tannin-lignin/formaldehyde and a tannin/lignin mass ratio of 1.25 and 1.28, respectively. In general, cross-linking in lignin 


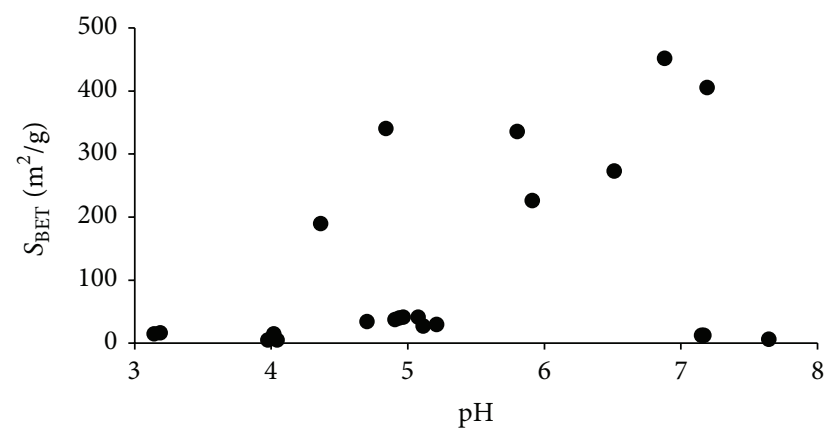

FIgURE 3: $S_{\text {BET }}$ in function of $\mathrm{pH}$.

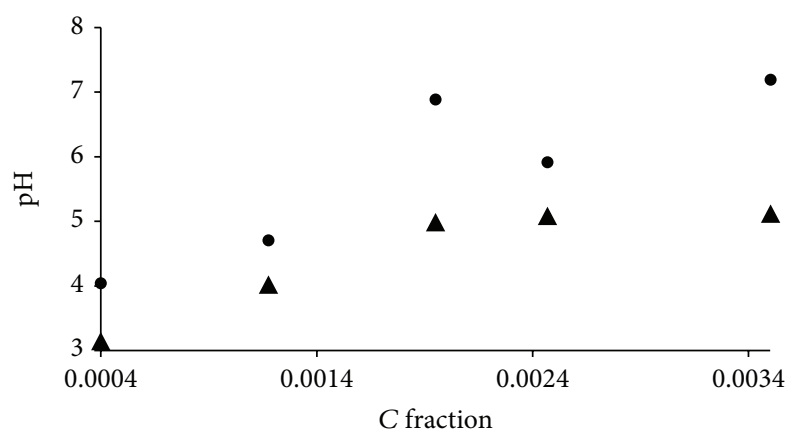

FIGURE 4: Mixture pH before cured in function of $C$ mass fraction: - $L$ mass fraction from 0.032 to $0.069 ; \boldsymbol{\Delta} L$ mass fraction from 0.087 to 0.140 .

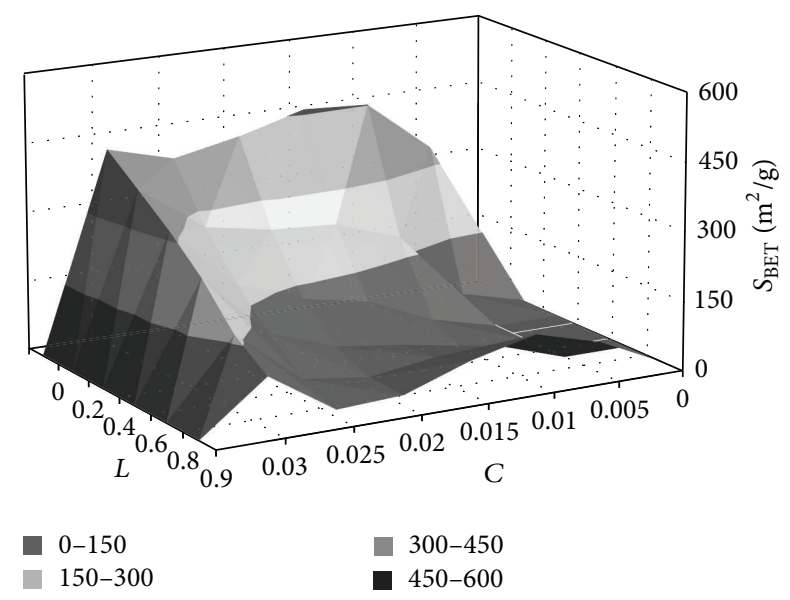

FIGURE 5: Xerogels specific surface area in function of their composition.

is poor because its molecular size does not allow a good packing for micropore and mesopore formation and mainly macropores were produced [14]. Nonwood lignins are more reactive than hard-wood lignins, but lignin used in this work has a higher molecular weight; no purifications process has been used, so its reactive sites are lower [46] and it could be a reason for a low $S_{\mathrm{BET}}$ in xerogels compared with other works.

Linear correlation between $S_{\mathrm{BET}}$ and micropore volume is found; therefore all analyses that were concluded for $S_{\mathrm{BET}}$ are valid for the micropores volume. At pH $7.16\left(S_{\mathrm{BET}} \sim 400 \mathrm{~m}^{2} / \mathrm{g}\right)$

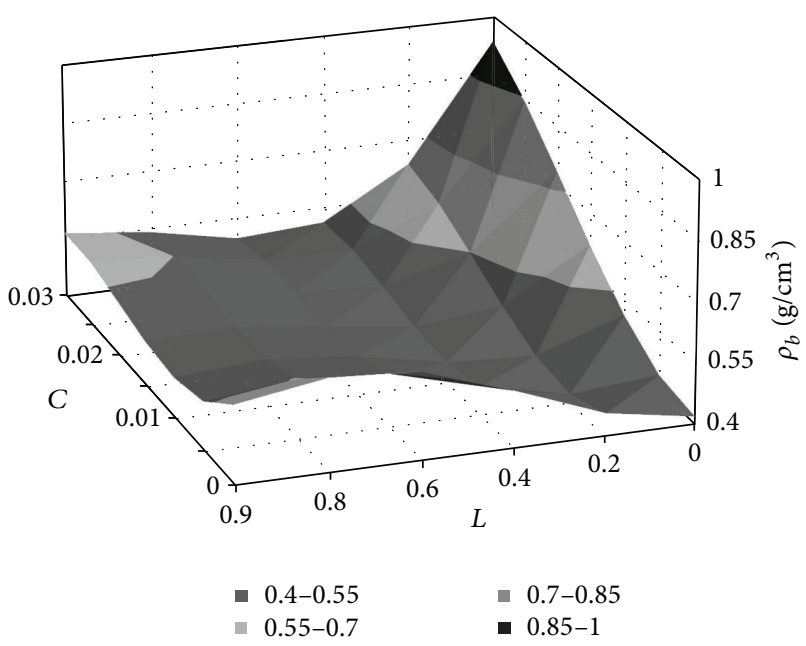

FIgURE 6: Xerogels bulk density in function of their composition.

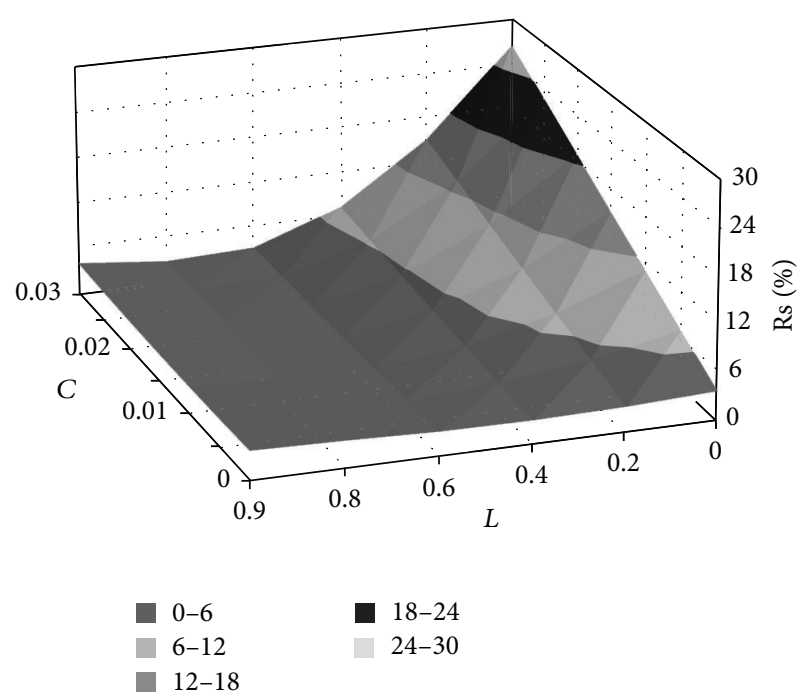

FIGURE 7: Xerogels shrinkage in function of their composition.

there are more micropores than mesopores; this result means that a high $\mathrm{pH}$ mainly micropores are formed and it is in accordance with previous works [30].

3.3.2. Shrinkage and Bulk Density Analysis. Bulk density varies from $0.42 \mathrm{~g} / \mathrm{cm}^{3}$ to $0.9 \mathrm{~g} / \mathrm{cm}^{3}$; minimum value corresponds to the higher water mass fraction used. Radial shrinkages are between $3.42 \%$ and $25.35 \%$. The lowest values are those with low catalyst. Bulk density and shrinkage are directly proportional as could be observed in Figures 6 and 7. Photo presented in Figure 8 shows different sample morphologies from the D-Optimal design assays.

Shrinkage is increased at high catalyst content. When the initial solution's $\mathrm{pH}$ is higher than 6.5 micropores formation is promoted, so the capillary pressure during the drying process is superior and shrinkage is augmented $[48,53]$. When there is a high shrinkage more micropores are formed and mesopores are reduced [15]. The small pore radius formation 


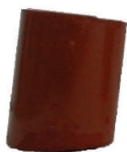

1

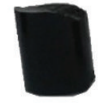

6

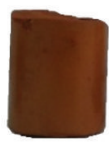

10

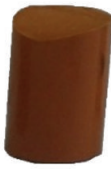

14

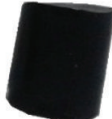

16
Figure 8: DO design samples photos.

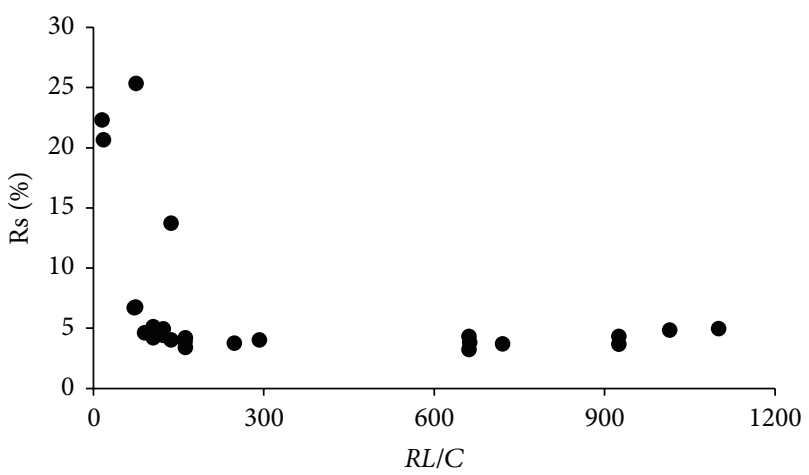

FIGURE 9: Radial shrinkage versus $R L / C$ in both designs, when $R / F$ mass ratio is around 1.6 .

is associated with the reaction rates of a parallel system of reaction, addition, and condensation. At high $\mathrm{pH}$, addition reaction is promoted and methylol derivatives that form small clusters are created [50]. For a high $L R F$ mass fraction, higher than $35 \%$, gelation ability is increased and also the formation of pores with smaller radius [13]. Shrinkage has a strong relation with $R L / C$; small values occurred when $R L / C$ was higher than 100 without any relationship with lignin or water quantity. In this point $\mathrm{pH}$ is around five, Figure 9.

According to Figures 6 and 7, lignin contributes to decreasing both properties; one reason is that lignin is a hard molecule; its rigid character is conjugated with gels based on hard nodules with a lower shrinkage [14]. Lignin dissolution is lower at low catalyst levels; when lignin is not dissolved its reactivity decreases and could act as filler.

Skeletal density has an average value of $1.20 \pm 0.03 \mathrm{~g} / \mathrm{cm}^{3}$; this value is the lowest for that reported for aerogels and cryogels $[14,15,48]$; it mainly could be for differences in composition and also could be due to lignin low skeletal density, $1.27 \mathrm{~g} / \mathrm{cm}^{3}$.

Overall porosity was found between 0.3 and 0.65 . In Figure 10 it could be observed how porosity has an inverse relationship with the amount of lignin and catalyst, opposed to the observed for the bulk density.

3.4. FTIR Characterization. Figure 11 shows the FTIR spectra of lignin and some of the xerogels obtained and in Table 7 the peaks present at lignin and xerogels are summarized. Lignin characteristic peaks are observed in $1510 \mathrm{~cm}^{-1}$ and $1594 \mathrm{~cm}^{-1}$ corresponding to the aromatic vibration guaiacyl and syringyl units, respectively. Also the peaks for expected functional groups are observed: a broad band from 3000 to $3500 \mathrm{~cm}^{-1}$ are hydroxyls; methylene and methyl groups

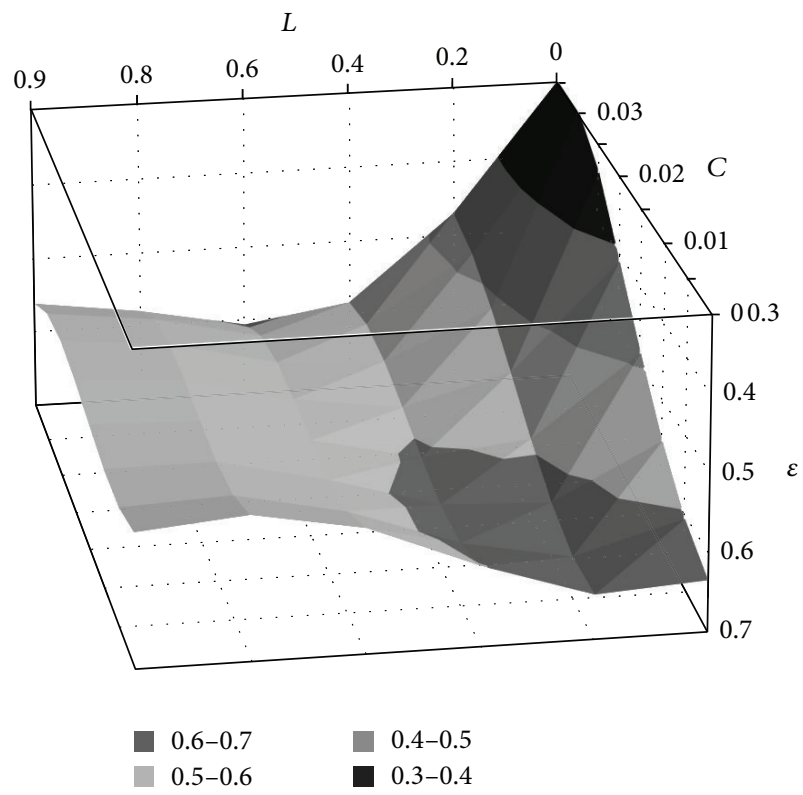

FiguRE 10: Xerogels porosity in function of their composition.

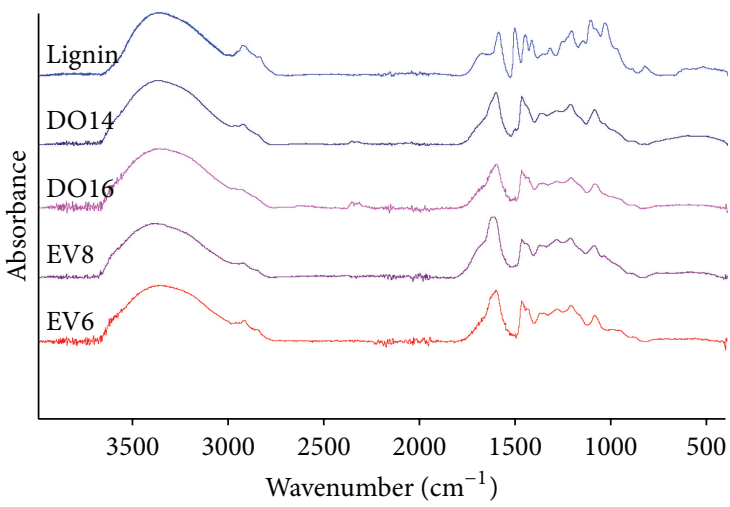

FIGURE 11: Lignin and some organic xerogels FTIR.

from 2900 to $2950 \mathrm{~cm}^{-1}$ and from 1460 to $1420 \mathrm{~cm}^{-1}$; methyl groups at $1375 \mathrm{~cm}^{-1}$ and, methylene and hydroxyl groups at $1330 \mathrm{~cm}^{-1}$. In $2850 \mathrm{~cm}^{-1}$ there are aromatic methoxy groups. The presence of $\mathrm{C}=\mathrm{O}$ at $1720 \mathrm{~cm}^{-1}$ is probably due to the form of precipitation of lignin in which the contact with acid causes partial degradation of the hemicelluloses present and some lignin. Carbonyls at $1214 \mathrm{~cm}^{-1}$ come from guaiacyl units. Additionally, C-O bonds are evidenced at 1260 (from guaiacyl units), 1220, 1080, and $1034 \mathrm{~cm}^{-1}$. Guaiacyl C-H and syringyl C-H evidence at $1140 \mathrm{~cm}^{-1}$ and at $854 \mathrm{~cm}^{-1} \mathrm{C}-\mathrm{H}$ out of plane vibrations of the guaiacyl units are shown $[15,43]$.

In xerogels, the broad band of hydroxyls at 3000 to $3500 \mathrm{~cm}^{-1}$ remains, indicating that free hydroxyl groups still exist. For all xerogels obtained, a peak at $1594 \mathrm{~cm}^{-1}$ can be observed in all spectra, while the peak at $1510 \mathrm{~cm}^{-1}$ disappears; this could be because guaiacyl units from lignin are more reactive and participate in addition reactions. At $1460 \mathrm{~cm}^{-1}, \mathrm{C}-\mathrm{H}$ deformation of methyl and methylene 


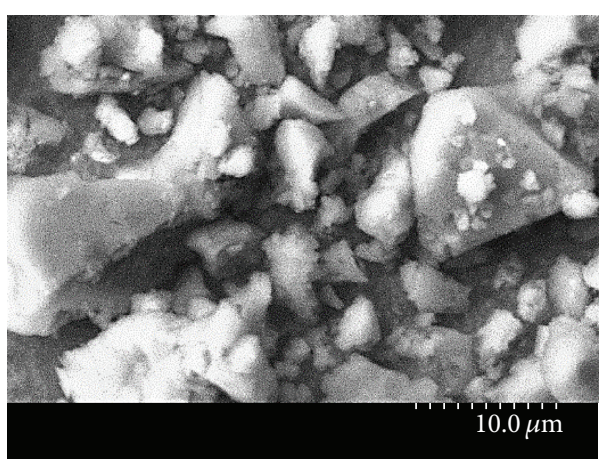

(a) Lignin

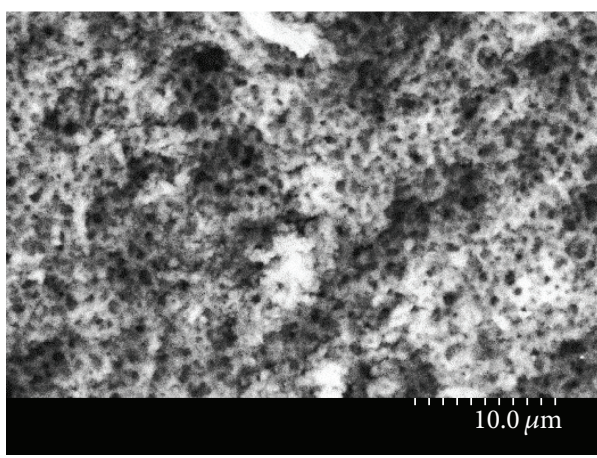

(c) $\mathrm{DO} 14$

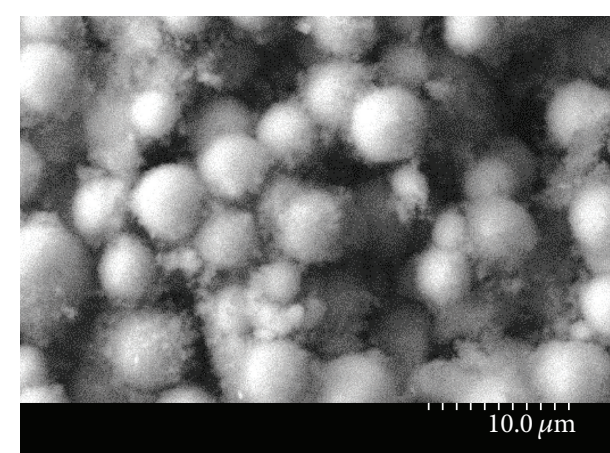

(b) DO9

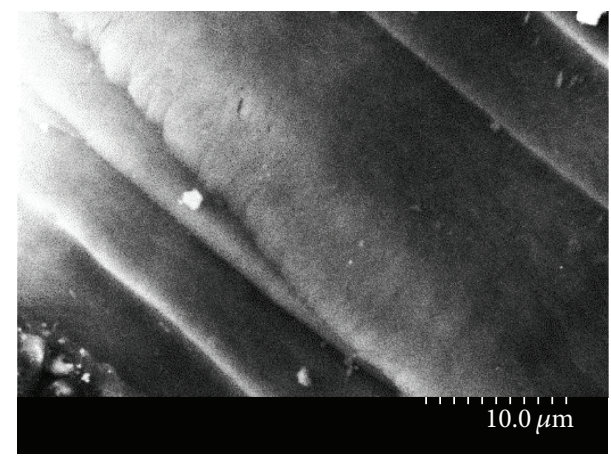

(d) Xerogel without lignin

FIGURE 12: Some SEM micrographs (3000x).

TABLE 7: Position and attribution of the IR absorption bands for lignin and xerogels.

\begin{tabular}{|c|c|}
\hline $\begin{array}{l}\text { Wavenumber } \\
(\mathrm{cm} 1)\end{array}$ & Band attribution \\
\hline $3412-3012$ & $v(\mathrm{OH})$ \\
\hline $2850-3006$ & $v_{\mathrm{as}}\left(\mathrm{CH}_{2}\right)$ \\
\hline 2850 & $v\left(\mathrm{CH}_{2}\right)$ in aromatic methoxy groups \\
\hline $1710^{\mathrm{s}}$ & $v(\mathrm{C}=\mathrm{O})$ not conjugated \\
\hline $1670^{\mathrm{s}}$ & $\nu(\mathrm{C}=\mathrm{O})$ conjugated ketones ${ }^{1}$ \\
\hline $1594-1613$ & $\delta(\mathrm{C}=\mathrm{C})$ aromatic rings \\
\hline 1510 & $\delta(\mathrm{C}=\mathrm{C})$ aromatic rings ${ }^{1}$ \\
\hline 1460 & $\delta\left(\mathrm{CH}_{2}\right)$ and $\left(\mathrm{CH}_{3}\right)^{\mathrm{x}}$ \\
\hline 1420 & $\delta$ (scissors) $\left(\mathrm{CH}_{2}\right)$ and $\left(\mathrm{CH}_{3}\right)^{1}$ \\
\hline $1375^{\mathrm{s}}$ & $\delta_{\text {sy }}\left(\mathrm{CH}_{3}\right)$ \\
\hline $1330^{\mathrm{s}}$ & $\gamma\left(\mathrm{CH}_{2}\right)$ and $\delta(\mathrm{O}-\mathrm{H})^{1}$ \\
\hline 1262 & $v(\mathrm{C}-\mathrm{O})$ \\
\hline 1220 & $v(\mathrm{C}-\mathrm{O})$ \\
\hline 1080 & $v(\mathrm{C}-\mathrm{O})$ in secondary alcohols and aliphatic ethers \\
\hline 1034 & $v_{\mathrm{sy}}(\mathrm{C}-\mathrm{O}-\mathrm{C})^{1}$ \\
\hline $810-902$ & $\begin{array}{l}\delta(\mathrm{C}-\mathrm{H}) \text { out of plane of aromatic rings and } \delta(\mathrm{C}-\mathrm{C}) \\
\text { in rings }\end{array}$ \\
\hline
\end{tabular}

$\nu$ : stretch; $\delta$ : deformation; $\gamma$ : rocking; sy: symmetrical; as: asymmetrical; s: shoulder; 1: exclusive peak for lignin; $\mathrm{x}$ : exclusive peak for xerogels.

groups presents. Also the $\mathrm{C}-\mathrm{O}$ bonds are observed. The absorption band at $1219 \mathrm{~cm}^{-1}$, stretching vibration of C-O-C, and the bending vibration of $-\mathrm{CH}_{2}$ at $1094 \mathrm{~cm}^{-1}$ reveal the three-dimensional network structure of xerogels [12].

Additional evidence of the participation of lignin in condensation reactions during gelation is the decreasing or vanishing of methoxyl groups, primary alcohols, and the $\mathrm{C}=\mathrm{O}$ bond is still observed in the spectrum in comparison with xerogels without lignin [54]. A broadening of the peaks at wavenumbers lower than $2000 \mathrm{~cm}^{-1}$ is observed from DO14 (xerogel with higher lignin content) to EV6, indicating a higher level of cross-linking per unit volume [55]. Several researches had demonstrated lignin reactivity not only with FTIR but also with Nuclear Magnetic Resonance (NMR) where orto and meta positions of lignin aromatic ring can react with resorcinol to yield polymeric products $[15,25]$.

In the SEM pictures (Figure 12), changes in morphology among each sample are observed, exhibiting only one phase without lignin agglomerations. In sample DO9, lignin might contribute to forming large microspheres aggregates; on the other hand, in sample DO14 a surface similar to common xerogels is observed, based on roughly spherical nodules arranged in a random packing [15]. Xerogel without lignin exhibits a uniform surface, consequently from a low $R L / C$ ratio that contributes to forming a more compact structure.

Solubility assay results are listed in Table 8 . It would be expected that if lignin remains in xerogel matrix as filler, a $\mathrm{pH} 12$ solution will solubilize all. But this is not the case; all solutions concentrations are lower than the calculated concentration obtained from the percentage of lignin in each dry xerogel. Although, xerogel without lignin 
TABLE 8: Xerogels and lignin solubility in pH 12 solution.

\begin{tabular}{lccc}
\hline Sample & $\begin{array}{c}L \\
\text { (\% dry basis })\end{array}$ & $\begin{array}{c}C_{x} \\
(\mathrm{~g} / \mathrm{L})\end{array}$ & $\begin{array}{c}C_{\mathrm{UV} 280 \mathrm{~nm}} \\
(\mathrm{~g} / \mathrm{L})\end{array}$ \\
\hline $0^{*}$ & 0 & 0 & 0.0073 \\
DO9 & 25.76 & 1.0303 & 0.0679 \\
DO14 & 17.53 & 0.7010 & 0.1087 \\
DO16 & 7.60 & 0.3039 & 0.0842 \\
Lignin & 100 & 4 & 3.8373 \\
\hline
\end{tabular}

${ }^{*}$ Xerogel prepared without lignin.

has some solubility in $\mathrm{pH} 12$ solutions, its contribution to the concentration is almost negligible. A linear correlation between lignin percentage and concentration also would be expected, but catalyst doses affect lignin dissolution in xerogels and its participation in reaction, so it must be taken in account.

\section{Conclusions}

Organic xerogels properties were accurately modeled with $R^{2}$ superior to $94 \%$, allowing properties prediction from components. Catalyst and water fraction have proportional influence on shrinkage; lignin, resorcinol, and formaldehyde have an inverse influence on shrinkage.

The resorcinol-formaldehyde mass ratio of 1.5 and water fraction lower than 0.55 show that with subcritical drying it is possible to produce xerogels with shrinkages lower than $5 \%$ allowing keeping shape and dimensions.

Catalyst has a strong influence in xerogels physical properties: with high catalyst proportion $(R L / C$ higher than $100)$ lignin dissolution was improved and increased the radial shrinkage and bulk density. It was found that the best $S_{\mathrm{BET}}$ values, $226-451 \mathrm{~m}^{2} / \mathrm{g}$, occurred with a $R L / C$ mass ratio from 70 to 134 that corresponds to initials $\mathrm{pH}$ from 5.91 to 7.19 .

Lignin contributes to lowering initial $\mathrm{pH}$ due to its acid character and also reduces shrinkage and $S_{\mathrm{BET}}$ due to its compact and rigid structure. Although lignin reduces the specific surface area, the cost benefits must be evaluated. The FTIR spectra show the participation of lignin with resorcinol and formaldehyde in addition and condensation reactions, mainly due to the hydroxymethyl groups that disappear in the xerogels spectrum.

\section{Conflict of Interests}

The authors declare that there is no conflict of interests regarding the publication of this paper.

\section{Acknowledgments}

The authors thank the Programa Nacional de Formación de Investigadores "Generación bicentenario" año 2011, Departamento de Ciencia, Tecnología e Innovación, Colciencias, and the Universidad Pontificia Bolivariana for doctoral study grant and financial support (Code: 113B-05/13-21).

\section{References}

[1] R. W. Pekala, "Low density, resorcinol-formaldehyde aerogels," USA Patent 4873218, 1989.

[2] L. Zubizarreta, J. A. Menéndez, N. Job et al., "Ni-doped carbon xerogels for $\mathrm{H}_{2}$ storage," Carbon, vol. 48, no. 10, pp. 2722-2733, 2010.

[3] A. K. Meena, G. K. Mishra, P. K. Rai, C. Rajagopal, and P. N. Nagar, "Removal of heavy metal ions from aqueous solutions using carbon aerogel as an adsorbent," Journal of Hazardous Materials, vol. 122, no. 1-2, pp. 161-170, 2005.

[4] Y. J. Lee, J. C. Jung, S. Park et al., "Preparation and characterization of metal-doped carbon aerogel for supercapacitor," Current Applied Physics, vol. 10, no. 3, pp. 947-951, 2010.

[5] J. A. Menéndez, E. J. Juárez-Pérez, E. Ruisánchez, E. G. Calvo, and A. Arenillas, "A microwave-based method for the synthesis of carbon xerogel spheres," Carbon, vol. 50, no. 10, pp. 35553560, 2012.

[6] D. Wu and R. Fu, "Synthesis of organic and carbon aerogels from phenol-furfural by two-step polymerization," Microporous and Mesoporous Materials, vol. 96, no. 1-3, pp. 115-120, 2006.

[7] C. Scherdel, R. Gayer, and G. Reichenauer, "Porous organic and carbon xerogels derived from alkaline aqueous phenolformaldehyde solutions," Journal of Porous Materials, vol. 19, no. 3, pp. 351-360, 2012.

[8] J. Sánchez-Martín, J. Beltrán-Heredia, and P. Gibello-Pérez, "Adsorbent biopolymers from tannin extracts for water treatment," Chemical Engineering Journal, vol. 168, no. 3, pp. 12411247, 2011.

[9] G. Amaral-Labat, L. I. Grishechko, V. Fierro, B. N. Kuznetsov, A. Pizzi, and A. Celzard, "Tannin-based xerogels with distinctive porous structures," Biomass and Bioenergy, vol. 56, pp. 437-445, 2013.

[10] P. J. M. Carrott, L. M. Marques, and M. M. L. R. Carrott, "Characterisation of the porosity of polymer and carbon aerogels containing $\mathrm{Fe}, \mathrm{Ni}$ or $\mathrm{Cu}$ prepared from 2,4-dihydroxybenzoic acid by $n$-nonane pre-adsorption and density functional theory," Microporous and Mesoporous Materials, vol. 131, no. 1-3, pp. 75-81, 2010.

[11] C. Moreno-Castilla, M. B. Dawidziuk, F. Carrasco-Marín, and Z. Zapata-Benabithe, "Surface characteristics and electrochemical capacitances of carbon aerogels obtained from resorcinol and pyrocatechol using boric and oxalic acids as polymerization catalysts," Carbon, vol. 49, no. 12, pp. 3808-3819, 2011.

[12] F. Chen and J. Li, "Synthesis and structural characteristics of organic aerogels with different content of lignin," Advanced Materials Research, vol. 113-116, pp. 1837-1840, 2010.

[13] F. Chen, M. Xu, L. Wang, and J. Li, "Preparation and characterization of organic aerogels from a lignin-resorcinolformaldehyde copolymer," BioResources, vol. 6, no. 2, pp. 1262 1272, 2011.

[14] L. I. Grishechko, G. Amaral-Labat, A. Szczurek et al., "New tannin-lignin aerogels," Industrial Crops and Products, vol. 41, no. 1, pp. 347-355, 2013.

[15] L. I. Grishechko, G. Amaral-Labat, A. Szczurek, V. Fierro, B. N. Kuznetsov, and A. Celzard, "Lignin-phenol-formaldehyde aerogels and cryogels," Microporous and Mesoporous Materials, vol. 168, pp. 19-29, 2013.

[16] V. K. Thakur and M. K. Thakur, "Recent advances in green hydrogels from lignin: a review," International Journal of Biological Macromolecules, vol. 72, pp. 834-847, 2015. 
[17] D. F. Albert, G. R. Andrews, R. S. Mendenhall, and J. W. Bruno, "Supercritical methanol drying as a convenient route to phenolic-furfural aerogels," Journal of Non-Crystalline Solids, vol. 296, no. 1-2, pp. 1-9, 2001.

[18] K. Kraiwattanawong, S. R. Mukai, H. Tamon, and A. W. Lothongkum, "Preparation of carbon cryogels from wattle tannin and furfural," Microporous and Mesoporous Materials, vol. 98, no. 1-3, pp. 258-266, 2007.

[19] D. Fengel and G. Wegener, Wood: Chemistry, Ultrastructure, Reactions, Verlag Kessel, Munich, Germany, 2003.

[20] K. Fu, Q. Yue, B. Gao, Y. Sun, and L. Zhu, "Preparation, characterization and application of lignin-based activated carbon from black liquor lignin by steam activation," Chemical Engineering Journal, vol. 228, pp. 1074-1082, 2013.

[21] Y. Ge, Z. Li, Y. Kong, Q. Song, and K. Wang, "Heavy metal ions retention by bi-functionalized lignin: synthesis, applications, and adsorption mechanisms," Journal of Industrial and Engineering Chemistry, vol. 20, no. 6, pp. 4429-4436, 2014.

[22] Suhas, P. J. M. Carrott, and M. M. L. Ribeiro Carrott, "Ligninfrom natural adsorbent to activated carbon: a review," Bioresource Technology, vol. 98, no. 12, pp. 2301-2312, 2007.

[23] D. Stewart, "Lignin as a base material for materials applications: chemistry, application and economics," Industrial Crops and Products, vol. 27, no. 2, pp. 202-207, 2008.

[24] A. Effendi, H. Gerhauser, and A. V. Bridgwater, "Production of renewable phenolic resins by thermochemical conversion of biomass: a review," Renewable and Sustainable Energy Reviews, vol. 12, no. 8, pp. 2092-2116, 2008.

[25] P. Truter, A. Pizzi, and H. Vermaas, "Cold-setting wood adhesives from kraft hardwood lignin," Journal of Applied Polymer Science, vol. 51, no. 7, pp. 1319-1322, 1994.

[26] T. Horikawa, J. Hayashi, and K. Muroyama, "Controllability of pore characteristics of resorcinol-formaldehyde carbon aerogel," Carbon, vol. 42, no. 8-9, pp. 1625-1633, 2004.

[27] D. Fairén-Jiménez, F. Carrasco-Marín, and C. Moreno-Castilla, "Porosity and surface area of monolithic carbon aerogels prepared using alkaline carbonates and organic acids as polymerization catalysts," Carbon, vol. 44, no. 11, pp. 2301-2307, 2006.

[28] R. Brandt and J. Fricke, "Acetic-acid-catalyzed and subcritically dried carbon aerogels with a nanometer-sized structure and a wide density range," Journal of Non-Crystalline Solids, vol. 350, pp. 131-135, 2004.

[29] C. I. Merzbacher, S. R. Meier, J. R. Pierce, and M. L. Korwin, "Carbon aerogels as broadband non-reflective materials," Journal of Non-Crystalline Solids, vol. 285, no. 1-3, pp. 210-215, 2001.

[30] N. Job, R. Pirard, J. Marien, and J.-P. Pirard, "Porous carbon xerogels with texture tailored by $\mathrm{pH}$ control during sol-gel process," Carbon, vol. 42, no. 3, pp. 619-628, 2004.

[31] C. S. Sharma, M. M. Kulkarni, A. Sharma, and M. Madou, "Synthesis of carbon xerogel particles and fractal-like structures," Chemical Engineering Science, vol. 64, no. 7, pp. 1536-1543, 2009.

[32] W. Jonglertjunya, T. Juntong, N. Pakkang, N. Srimarut, and C. Sakdaronnarong, "Properties of lignin extracted from sugarcane bagasse and its efficacy in maintaining postharvest quality of limes during storage," LWT-Food Science and Technology, vol. 57, no. 1, pp. 116-125, 2014.

[33] E. J. Zanto, S. A. Al-Muhtaseb, and J. A. Ritter, "Sol-gel-derived carbon aerogels and xerogels: design of experiments approach to materials synthesis," Industrial \& Engineering Chemistry Research, vol. 41, no. 13, pp. 3151-3162, 2002.
[34] J. A. Cornell, Experiments with Mixtures: Designs, Models, and the Analysis of Mixture Data, John Wiley \& Sons, New York, NY, USA, 3rd edition, 2011.

[35] N. Rey-Raap, J. A. Menéndez, and A. Arenillas, "RF xerogels with tailored porosity over the entire nanoscale," Microporous and Mesoporous Materials, vol. 195, pp. 266-275, 2014.

[36] G. Amaral-Labat, A. Szczurek, V. Fierro, A. Pizzi, and A. Celzard, "Systematic studies of tannin-formaldehyde aerogels: preparation and properties," Science and Technology of Advanced Materials, vol. 14, no. 1, Article ID 015001, 2013.

[37] N. Rey-Raap, J. A. Menéndez, and A. Arenillas, "Simultaneous adjustment of the main chemical variables to fine-tune the porosity of carbon xerogels," Carbon, vol. 78, pp. 490-499, 2014.

[38] K. Forss, R. Kokkonen, and P. E. Sågfors, "Determination of the molar mass distribution of lignins by gel permeation chromatography," in Lignin Properties and Materials, chapter 9, pp. 124-133, American Chemical Society, Washington, DC, USA, 1989.

[39] S. Brunauer, P. H. Emmett, and E. Teller, "Adsorption of gases in multimolecular layers," Journal of the American Chemical Society, vol. 60, no. 2, pp. 309-319, 1938.

[40] E. P. Barrett, L. G. Joyner, and P. P. Halenda, "the determination of pore volume and area distributions in porous substances. I. Computations from nitrogen isotherms," Journal of the American Chemical Society, vol. 73, no. 1, pp. 373-380, 1951.

[41] S. J. Gregg and K. S. Sing, Adsorption, Surface Area, and Porosity, Academic Press, London, UK, 2nd edition, 1982.

[42] R. Sun, J. M. Lawther, W. B. Banks, and B. Xiao, "Effect of extraction procedure on the molecular weight of wheat straw lignins," Industrial Crops and Products, vol. 6, no. 2, pp. 97-106, 1997.

[43] A. Mancera, V. Fierro, A. Pizzi et al., "Physicochemical characterisation of sugar cane bagasse lignin oxidized by hydrogen peroxide," Polymer Degradation and Stability, vol. 95, no. 4, pp. 470-476, 2010.

[44] R. Sun, J. Tomkinson, and G. L. Jones, "Fractional characterization of ash-AQ lignin by successive extraction with organic solvents from oil palm EFB fibre," Polymer Degradation and Stability, vol. 68, no. 1, pp. 111-119, 2000.

[45] D. M. Smith, G. W. Scherer, and J. M. Anderson, "Shrinkage during drying of silica gel," Journal of Non-Crystalline Solids, vol. 188, no. 3, pp. 191-206, 1995.

[46] S. Laurichesse and L. Avérous, "Chemical modification of lignins: towards biobased polymers," Progress in Polymer Science, vol. 39, no. 7, pp. 1266-1290, 2014.

[47] E. G. Calvo, Á. Menéndez, and A. Arenillas, "Designing nanostructured carbon xerogels," in Nanomaterials, chapter 9, InTech, Rijeka, Croatia, 2011.

[48] A. Léonard, S. Blacher, M. Crine, and W. Jomaa, "Evolution of mechanical properties and final textural properties of resorcinol-formaldehyde xerogels during ambient air drying," Journal of Non-Crystalline Solids, vol. 354, no. 10-11, pp. 831-838, 2008.

[49] R. Petričević, G. Reichenauer, V. Bock, A. Emmerling, and J. Fricke, "Structure of carbon aerogels near the gelation limit of the resorcinol-formaldehyde precursor," Journal of NonCrystalline Solids, vol. 225, no. 1-3, pp. 41-45, 1998.

[50] N. Job, F. Panariello, J. Marien, M. Crine, J.-P. Pirard, and A. Léonard, "Synthesis optimization of organic xerogels produced from convective air-drying of resorcinol-formaldehyde gels," Journal of Non-Crystalline Solids, vol. 352, no. 1, pp. 24-34, 2006. 
[51] O. Czakkel, K. Marthi, E. Geissler, and K. László, "Influence of drying on the morphology of resorcinol-formaldehyde-based carbon gels," Microporous and Mesoporous Materials, vol. 86, no. 1-3, pp. 124-133, 2005.

[52] K. V. Sarkanen and H. L. Hergert, Lignins: Occurrence, Formation, Structure, and Reactions, Wiley-Interscience, New York, NY, USA, 1971.

[53] S. Mezzavilla, C. Zanella, P. R. Aravind, C. D. Volpe, and G. D. Sorarù, "Carbon xerogels as electrodes for supercapacitors. The influence of the catalyst concentration on the microstructure and on the electrochemical properties," Journal of Materials Science, vol. 47, no. 20, pp. 7175-7180, 2012.

[54] R. W. Pekala, "Organic aerogels from the polycondensation of resorcinol with formaldehyde," Journal of Materials Science, vol. 24, no. 9, pp. 3221-3227, 1989.

[55] A. Szczurek, G. Amaral-Labat, V. Fierro, A. Pizzi, and A. Celzard, "The use of tannin to prepare carbon gels. Part II. Carbon cryogels," Carbon, vol. 49, no. 8, pp. 2785-2794, 2011. 

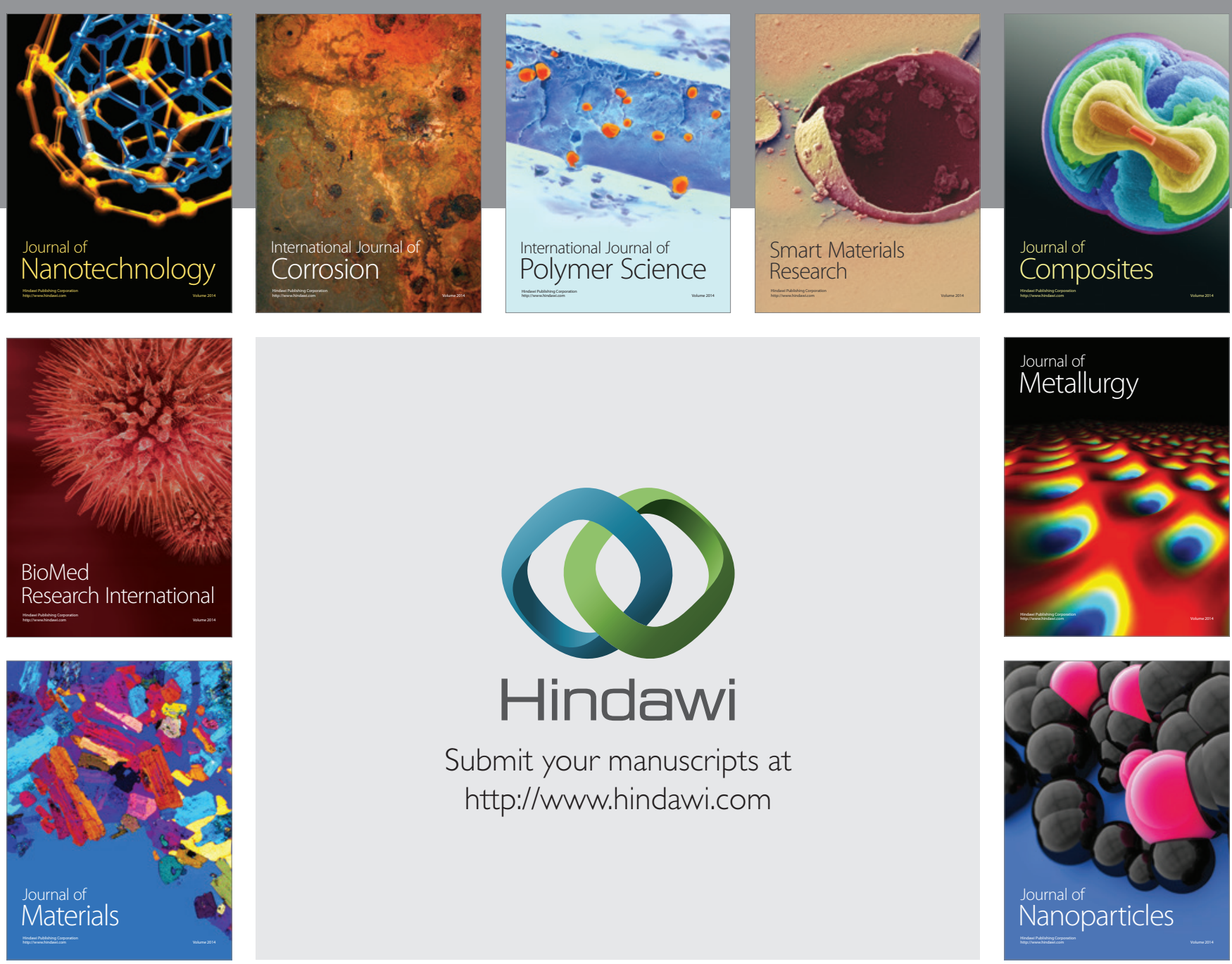

Submit your manuscripts at http://www.hindawi.com
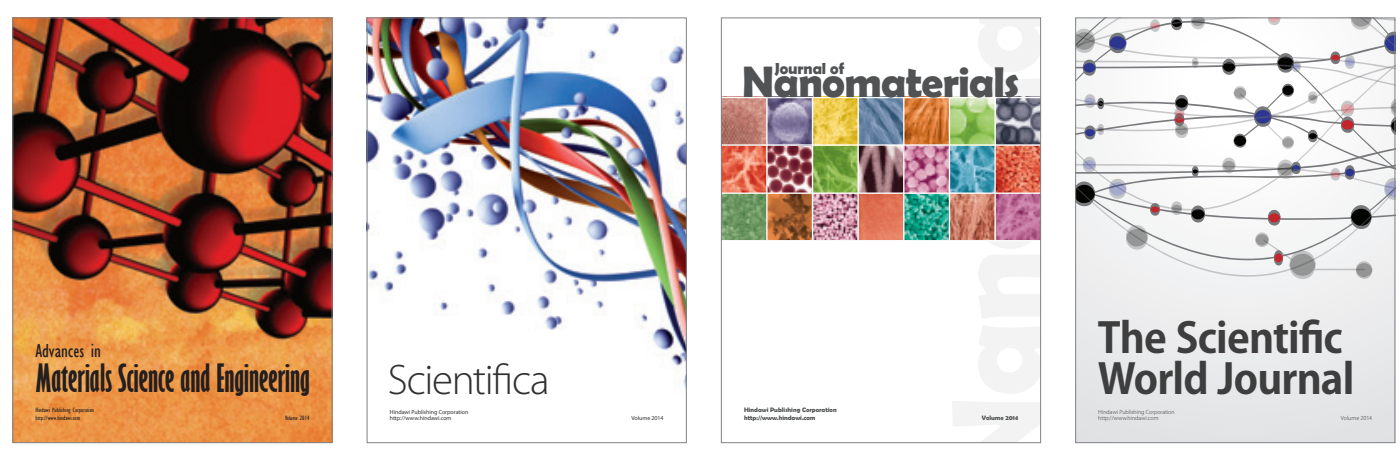

\section{The Scientific World Journal}
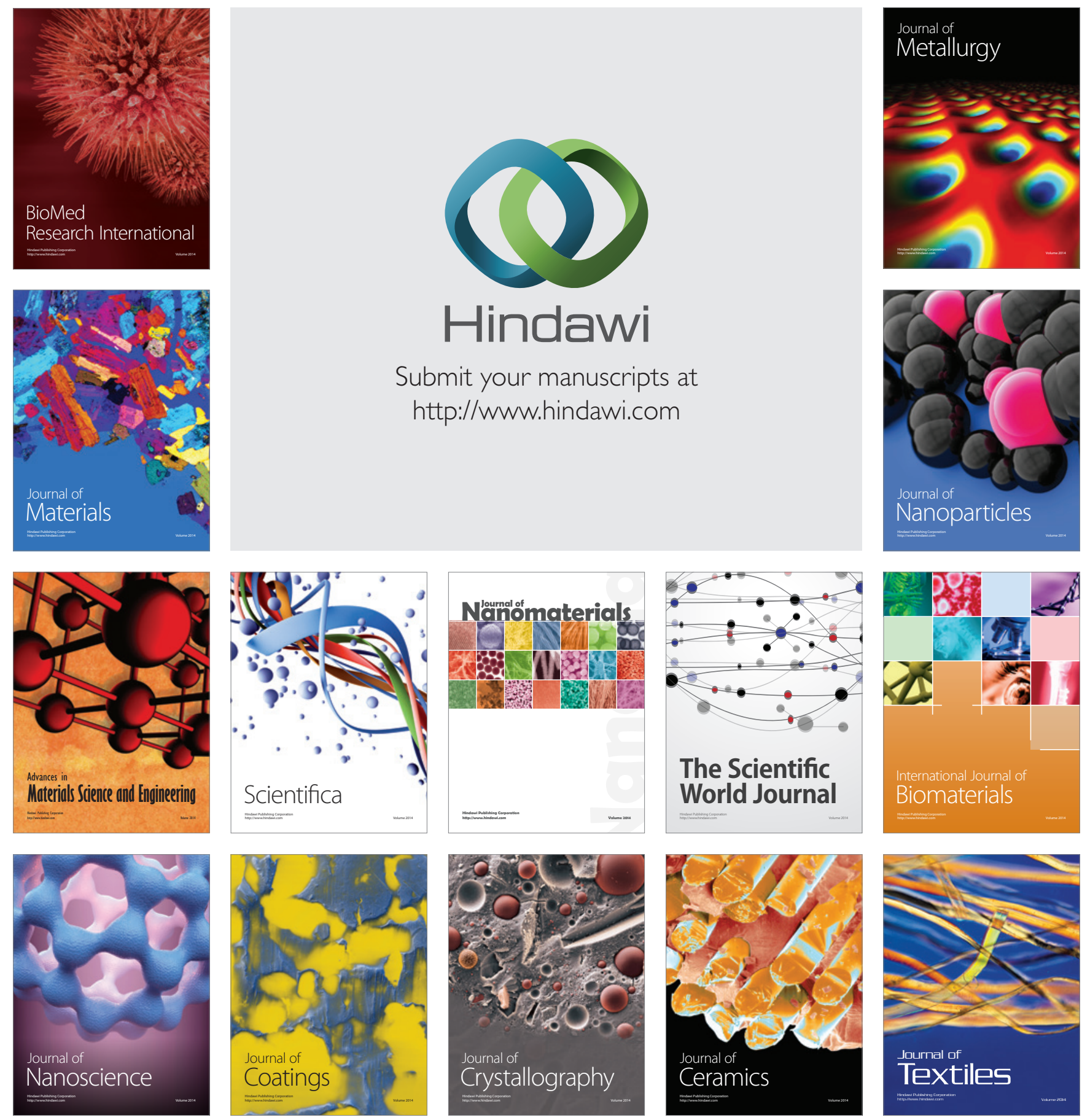